\title{
Exposure to formaldehyde at therapeutic levels decreases peripheral blood lymphocytes and hematopoietic progenitors in the pronephros of tilapia Oreochromis niloticus
}

\author{
S. D. Holladay ${ }^{1}$, B. J. Smith ${ }^{2}$, R. M. Gogal Jr. ${ }^{1, *}$ \\ ${ }^{1}$ Department of Anatomy and Radiology, College of Veterinary Medicine, Athens, Georgia 30602-7382, USA \\ ${ }^{2}$ Department of Biomedical Sciences and Pathobiology, Virginia-Maryland Regional College of Veterinary Medicine, \\ Blacksburg, Virginia 24061-0442, USA
}

\begin{abstract}
Formaldehyde (HCHO) was recently detected at concentrations above the cancer benchmark in $90 \%$ of 60000 surveyed United States census tracks. Formaldehyde leaches into and mixes with water extremely well, exposing aquatic life. Further, formaldehyde is used therapeutically in aquaculture to remove external protozoa and other parasites from fish. The present study was undertaken to determine if sub-acute HCHO causes immunologic changes in tilapia Oreochromis niloticus. Fish were exposed to 0, 50, or $150 \mathrm{ppm}$ of HCHO. Immune parameters examined included blood hematology, spleen/body weight ratio, spleen and pronephros total cellularity, leukocyte blastogenesis, and natural killer cell cytotoxicity. Organ/body weight ratios and total cellularity were not different from controls. Similarly, mitogen response and natural killer cell function were unchanged. Peripheral blood lymphocytes decreased as HCHO exposure increased. Formaldehyde exposure also decreased the number of progenitor cells in the fish pronephros. These observations suggest possible immunosuppressive effects of HCHO in fish.
\end{abstract}

KEY WORDS: Formaldehyde $\cdot$ Immune system $\cdot$ Fish $\cdot$ Tilapia

\section{INTRODUCTION}

Formaldehyde (HCHO) is an industrial chemical known to be an inhalational toxicant (McNary \& Jackson 2007), dermal contact irritant (Hilton et al. 1996), mutagen (Odeigah 1997), and carcinogen (McCarthy et al. 2009). Exposure to HCHO has been shown to exert deleterious effects in both laboratory animals and humans, with the precise effect varying based on concentration, exposure route, and duration of exposure. Despite these concerns, $\mathrm{HCHO}$ is nonetheless widely used in numerous applications, with some of its uses being indispensable in the health field (Balamurugan et al. 2004).

Normal husbandry practices in the commercial aquaculture industry include therapeutic immersion of fish in formalin solutions to remove external parasites, including protozoa (Bodensteiner et al. 1993, MacLean et al. 2006, Lahnsteiner \& Weismann 2007). Formaldehyde also has numerous product manufacturing uses, playing an important role in production of foam insulation, carpeting, pressed wood products (Maddalena et al. 2009), as well as the more commonly known use in the preparation of laboratory specimens for anatomical study. Such broad use of $\mathrm{HCHO}$ in numerous venues has resulted in widespread environmental contamination with this chemical. A 1998 report from the United States Environmental Protection Agency (US EPA) indicated that $\mathrm{HCHO}$ was not only detected, but also found at levels exceeding the cancer benchmark concentration in approximately $90 \%$ of the 60000 census tracks 
(geographic study regions) measured throughout the United States (Woodruff et al. 1998). Formaldehyde is also a common aquatic contaminant that mixes with water extremely well (Murai et al. 2008). Contamination of aquatic environments and the resulting exposure of aquatic life to this chemical is thus a concern.

The immune response of fish is becoming increasingly characterized in the laboratory. Though the humoral response of the piscine immune system relies more heavily on IgM-like immunoglobin than other isotypes of antibody, the immune response in fish has been shown to be similar to that of mammals in many regards (Smith et al. 1999). Indeed, recent studies have indicated that fish may be a good alternate species to rodents for evaluating chemical-induced immunotoxicity (Gogal et al. 1999, Müller et al. 2009, Iwanowicz et al. 2009). Regarding environmental exposure, fish have been shown to respond in a recognizable manner to exposure to many chemicals, including various water-borne contaminants. A study on metallic aquatic pollutants has demonstrated exposure-related changes in cell-mediated, humoral, and innate immunity (Zelikoff et al. 1995). Another study showed that lymphoproliferative responses of fish found in sites contaminated with polycyclic aromatic hydrocarbons (PAH) decreased (Faisal \& Huggett 1993).

Because HCHO, among chemicals, is known to contaminate various bodies of water, possible immunotoxicant effects of $\mathrm{HCHO}$ on the piscine immune system are of interest from the perspective of water contamination. Despite diverse indications that $\mathrm{HCHO}$ has some effect on the immune system, results of studies investigating numerous immune parameters including functional tests (Dean et al. 1984) have indicated that effects of inhalant $\mathrm{HCHO}$ exposure is not overtly immunotoxic in mice. Indeed, in that study, an apparent immunostimulatory effect was observed in the form of an increase in resistance to bacterial challenge. Given that many similarities between fish and mammals have been demonstrated in response to chemicals that are known immunotoxicants (Gogal et al. 1999), the question also arises whether formaldehyde has an immunomodulatory effect in fish. Examination of possible effects of $\mathrm{HCHO}$ exposure on the immune system of fish is of interest from each of these perspectives. Moreover, completion of such an investigation would also further the characterization of the piscine immune response as either fundamentally similar to or different from that of mammals. The present study investigated the effects of $\mathrm{HCHO}$ exposure on the piscine immune system, employing tests from the National Institute of Environmental Health Sciences' (NIEHS) National Toxicology Program (NTP)-approved testing battery (Dean 2004) in a laboratory environment. Nile tilapia
Oreochromis niloticus were selected for study as a high-production, relevant, and economically important species (Gogal et al. 1999).

\section{MATERIALS AND METHODS}

Fish. Pathogen-free Nile tilapia Oreochromis niloticus were hatched, reared, and maintained at the Aquatic Medicine Laboratory at the Virginia-Maryland Regional College of Veterinary Medicine. All experiments were approved prior to initiation by the Virginia Tech Animal Care and Use Committee. Throughout the study, all fish were then cared for and maintained in accordance with Virginia Tech institutional guidelines.

The fish were fed a commercial pelleted diet (Zeigler Brothers) that was administered once daily at approximately $3 \%$ of body weight. Water quality analysis was performed daily, and included the values of ammonia and nitrite levels, $\mathrm{pH}$, and temperature. During rearing, fish were maintained in tanks provided with continuous filtration and aeration, with water temperature maintained at $28 \pm 4.0^{\circ} \mathrm{C}$ and lighting maintained automatically on a $12 \mathrm{~h}$ light: $12 \mathrm{~h}$ dark cycle. Sample size for each experiment consisted of 3 fish. Range-finding studies for selecting $\mathrm{HCHO}$ exposure levels utilized fish within a specified weight range $(65 \pm 18 \mathrm{~g})$; these were arbitrarily selected and transferred to $80 \mathrm{l}$ tanks that had been partitioned to individually accommodate 3 fish per tank. Larger fish were necessary for the immunerelated experiments in order to yield adequate numbers of cells. These larger fish ( $\mathrm{n}=9$ per control or treatment group) were again of uniform size and weight $(150 \pm 35 \mathrm{~g})$, arbitrarily selected, and transferred to $300 \mathrm{l}$ tanks that also had been partitioned to individually accommodate 3 fish per tank. Following transference, monitoring of water quality values, as well as maintenance of filtration and the light/dark cycle, was performed as previously described. Fish were allowed to acclimate to the study tanks for $14 \mathrm{~d}$ prior to exposure to formalin.

Exposure to formalin. Limited data were available regarding the toxic effects of $\mathrm{HCHO}$ in tilapia; thus, initial range-finding studies with 3 fish per group were conducted with exposure to $0,50,100,150$, and $250 \mathrm{ppm}$. Limited signs of overt toxicity were observed at $250 \mathrm{ppm} \mathrm{HCHO}$, primarily as a reduction in motion. Based on the results of these range-finding studies, for the immunologic evaluations, only 0,50 , and $150 \mathrm{ppm}$ exposures were used, with 9 fish per group. In all treatments, fish were placed in a HCHO tank for $30 \mathrm{~min}$ every other day for a total of 2 treatments. The fish were sampled $48 \mathrm{~h}$ after the last exposure. 
Peripheral blood leukocyte collection and enumeration. In this part of the study, 3 replicates were run (thus summed $\mathrm{n}=9$ fish per dose group). Fish were anesthetized using tricaine methane sulfonate (MS222, Sigma). Blood was collected from the caudal tail vein using a 21-gauge needle and a $1 \mathrm{ml}$ syringe. Blood was transferred to a heparin-treated pediatric tube, reserving sufficient blood to prepare duplicate blood smears from each fish. The slides were air dried, fixed in $95 \%$ methanol, and stained with modified Wright's stain (Sigma). Differential leukocyte counts (lymphocytes, basophils, eosinophils, monocytes, and heterophils) were performed at $100 \times$ under oil immersion. To determine total blood cellularity, an aliquot of the heparin-treated blood sample from the pediatric tube was serially diluted and stained with Natt-Herrick stain and enumerated with a hemacytometer. Total cellularity per milliliter was reported.

Spleen and head kidney (pronephros) collection and enumeration. In this part of the study, 3 replicates were run (thus summed $n=9$ fish per dose group). On completion of venipuncture, each fish was euthanized by blunt cranial trauma while still anesthetized. The body weight of the fish was determined and recorded. The spleen and head kidney (pronephros) were then isolated from each fish, the spleens weighed, and each organ (spleen and head kidney) individually placed in a $60 \times 15 \mathrm{~mm}$ Petri dish containing incomplete RPMI-1640 (RPMI 1640 containing $2 \mathrm{mmol} \mathrm{l}^{-1}$ glutamine, $25 \mathrm{mmol} \mathrm{l}^{-1}$ HEPES, $20 \mathrm{mmol} \mathrm{l}^{-1}$ glucose, and $25 \mu \mathrm{g} \mathrm{ml}^{-1}$ gentamicin). Spleens were dissociated over a Sieves screen (Sigma, Chemical Co.) using curved forceps. Splenic cell suspensions were then washed twice by centrifugation $\left(200 \times g, 5 \mathrm{~min} ; 22^{\circ} \mathrm{C}\right)$ in culture medium, resuspended in $1 \mathrm{ml}$ of culture medium, and counted using an electronic cell counter (CASY 1; Cell Tools). Pronephric cell suspensions were prepared in a manner identical to that described for splenic cells.

Cyto-centrifugation (cytospin) phronephros leukocyte differentials. A $200 \mu \mathrm{l}$ aliquot of isolated pronephric leukocytes $\left(1.0 \times 10^{6}\right.$ cells $)$ was placed into a cytocentrifugation chamber (Cyto-TEK) containing $250 \mu \mathrm{l}$ phosphate-buffered saline and $50 \mu$ of $15 \%$ BSA (Sigma). The cells were spun at $50 \times g$ for $5 \mathrm{~min}$ at $23^{\circ} \mathrm{C}$. The slides were then fixed with $95 \%$ methanol and stained with modified Wright's stain (Sigma). Slides were covered with a coverslip and sealed with Permount (Fisher Scientific). Cells were examined under oil immersion at $100 \times$. The number of leukocytes counted was reported as a percentage of total counts, with 100 cells counted per cytospin slide.

Mitogen stimulation assay. Using 96-well roundbottom tissue culture plates (Corning), $100 \mu$ l aliquots of $5.0 \times 10^{6}$ cells ml ${ }^{-1}$ Lymphoprep-enriched pronephric leukocytes were added to triplicate wells containing
$100 \mu \mathrm{l}$ of either RPMI-1640 medium alone or medium plus phytohemagglutinin (PHA, Sigma), phorbol 12myristate 12-acetate (PMA, Sigma) and ionomycin (Ion, Sigma). The cells were incubated overnight in a humidified incubator at $28^{\circ} \mathrm{C}$ and $5 \% \mathrm{CO}_{2}$. After $24 \mathrm{~h}$ of incubation, $20 \mu \mathrm{l}$ of Alamar Blue dye (Accumed Internation) was added to each well and the plates were returned to the incubator. Differences in the specific absorbance of the oxidized form of this dye (600 nm) reflect the level of proliferation (Ahmed et al. 1994). Then, $48 \mathrm{~h}$ after the dye was added, the plates were removed from the incubator and the absorbance was measured at 570 and $600 \mathrm{~nm}$ with a kinetic microplate reader (Molecular Devices). The specific absorbance of the unstimulated cells (in medium alone) was subtracted from the specific absorbance of the PHA-stimulated cells to yield a change in specific absorbance.

Chromium-release assay. Splenic natural killer cell cytotoxicity against target tumor cells was measured using the standard chromium-release assay. Briefly, lymphoprep-separated splenic cells $\left(10.0 \times 10^{6}\right.$ cells $\mathrm{ml}^{-1}$ ) were aliquoted into quadruplicate wells of a 96 well tissue culture plate. The cells were serially diluted such that the ratio of effector to target cells was 50:1, $25: 1$, and $12.5: 1$ when $2.0 \times 10^{5}$ cells $\mathrm{ml}^{-1}$ of ${ }^{51} \mathrm{Cr}-$ tagged YAC-1 tumor cells were added to each well. The plates were incubated overnight at $28^{\circ} \mathrm{C}$ and $5 \%$ $\mathrm{CO}_{2}$. The cells were harvested with the skatron technique as previously described (Gogal et al. 1999) and counted on a Packard Cobra II gamma counter. Values were reported as the percentage of ${ }^{51} \mathrm{Cr}$ release (CPM) defined by the equation (Hudson \& Hay 1989):

$$
\begin{aligned}
& \text { Percent specific release }= \\
& \quad 100 \times\left(\mathrm{CPM}_{\exp }-\mathrm{CPM}_{\min }\right) /\left(\mathrm{CPM}_{\max }-\mathrm{CPM}_{\min }\right)
\end{aligned}
$$

where 'exp' represents experimental, 'min' represents minimum or spontaneous release, and ' $\mathrm{max}^{\prime}$ represents maximum or lysed cell release.

Statistical analysis. Data were expressed as the arithmetical mean \pm SEM. Analysis of variance (ANOVA) was used with Dunnett's $t$-test to compare means of treatment groups. Results described as different show a significant difference from the control, $\mathrm{p}<0.05$.

\section{RESULTS}

\section{Peripheral blood leukocyte collection and enumeration}

Total peripheral blood leukocyte cellularity was unchanged at any HCHO exposure level (Fig. 1). Cell types measured included lymphocytes, basophils, eosinophils, monocytes, and heterophils. Among these, only the percent of peripheral blood lymphocytes was significantly decreased by 150 ppm HCHO exposure (Fig. 2). 




Fig. 1. Oreochromis niloticus. Peripheral blood leukocyte cellularity (cells ml-1) in fish exposed to 0,50 , or $150 \mathrm{ppm}$ formaldehyde in water for $30 \mathrm{~min}$, every other day for 2 treatments

\section{Spleen/body weight ratio and splenic and pronephric cellularity}

The spleen/body weight ratio showed a high level of variability in all experiments (Fig. 3) and was not significantly changed by $\mathrm{HCHO}$ exposure in any replicate experiment. Similarly, neither splenic nor pronephric cellularity were significantly changed at any HCHO dosage (Fig. 4A,B).

\section{Cyto-centrifugation leukocyte differentials}

Fish exposed to $\mathrm{HCHO}$ demonstrated a significant decrease in the percentage of progenitor cells in the pronephros (Table 1). The total number of progenitor cells in each experimental group (i.e. the product of total organ cellularity $\times$ percentage of progenitors) was $40.5 \times 10^{6}$ cells in control fish, $37.6 \times 10^{6}$ cells at $50 \mathrm{ppm}$, and $28.2 \times 10^{6}$ cells at $150 \mathrm{ppm}$, showing similar decrease after HCHO. However, pronephros cellularity determination is naturally subject to somewhat high variability (Hart et al. 1997). For this reason, Table 1 reports only the percent composition results as the



Fig. 2. Oreochromis niloticus. Peripheral blood lymphocyte cellularity (cells ml ${ }^{-1}$ ) in fish exposed to 0,50 , or $150 \mathrm{ppm}$ formaldehyde in water for $30 \mathrm{~min}$, every other day for 2 treatments. ${ }^{*}$ Different from control, $\mathrm{p}<0.05$



Fig. 3. Oreochromis niloticus. Spleen/body weight ratio in fish exposed to 0,50 , or $150 \mathrm{ppm}$ formaldehyde in water for $30 \mathrm{~min}$, every other day for 2 treatments

probably more reliable data. In contrast to reduced percentages of progenitors, lymphocytic cells in the pronephros showed increased percentages at both levels of enriched $\mathrm{HCHO}$ exposure.

\section{Functional assays}

The mitogen stimulation assay showed no significant difference among treatment groups at either level of enriched dosage (Table 2). Similarly, the ${ }^{51} \mathrm{Cr}$ release assay demonstrated no treatment-related differences (data not shown).



Fig. 4. Oreochromis niloticus. Leukocyte cellularity in the (A) spleen and (B) pronephros in fish exposed to 0,50, or $150 \mathrm{ppm}$ formaldehyde in water for $30 \mathrm{~min}$, every other day for 2 treatments 
Table 1. Oreochromis niloticus. Leukocyte percentage in the pronephros. ${ }^{*} \mathrm{p}<0.05$ (n $=4$ fish treatment $^{-1}$ experiment $^{-1}$ )

\begin{tabular}{llrrr}
$\begin{array}{l}\text { Conc. } \\
(\mathrm{ppm})\end{array}$ & Lymphocyte Macrophage Heterophil & Progenitors \\
\hline 0 & $18.5 \pm 2.6$ & $10.6 \pm 1.9$ & $>1$ & $64.3 \pm 4.3$ \\
50 & $36.5 \pm 4.1^{*}$ & $13.8 \pm 2.7$ & $>1$ & $47.3 \pm 1.7^{*}$ \\
150 & $30.5 \pm 6.5^{*}$ & $9.3 \pm 1.8$ & $>1$ & $47.0 \pm 2.9^{*}$ \\
\hline
\end{tabular}

Table 2. Oreochromis niloticus. Mitogen proliferation of cultured fish splenocytes. Values for phytohemagglutinin (PHA) 1.0 $\mu \mathrm{g} \mathrm{ml}^{-1}$ are reported as $\Delta$ specific absorbance $(\mathrm{n}=4$ fish treatment $^{-1}$ experiment ${ }^{-1}$ ). PMA: phorbol 12-myristate 12-acetate. Ion: ionomycin. PMA/Ion: $10 \mathrm{ng} \mathrm{m}{ }^{-1} \mathrm{PMA}+200 \mathrm{pg} \mathrm{ml}^{-1}$ Ion

\begin{tabular}{|lccc|}
\hline $\begin{array}{l}\text { Conc. } \\
(\mathrm{ppm})\end{array}$ & $\begin{array}{c}\text { PHA } \\
\left(1.0 \mu \mathrm{g} \mathrm{m}^{-1}\right)\end{array}$ & $\begin{array}{c}\text { PHA } \\
\left(10.0 \mu \mathrm{g} \mathrm{ml}^{-1}\right)\end{array}$ & PMA/Ion \\
\hline 0 & $0.068 \pm 0.033$ & $0.223 \pm 0.038$ & $0.353 \pm 0.033$ \\
50 & $0.016 \pm 0.009$ & $0.175 \pm 0.071$ & $0.310 \pm 0.034$ \\
150 & $0.095 \pm 0.025$ & $0.301 \pm 0.044$ & $0.327 \pm 0.085$ \\
\hline
\end{tabular}

\section{DISCUSSION}

Although shown to be a carcinogen (Vasudeva \& Anand 1996) and mutagen (Mackerer et al. 1996), formaldehyde has been classified as a non-immuntoxic chemical based on rodent studies (Arts et al. 1997, Casanova \& Heck 1997), as well as on observed effects in vitro and in vivo (Mennear 1997). Nonetheless, its identification as a carcinogen suggests the possibility that $\mathrm{HCHO}$ may induce some immune effects. Various reports of HCHO's effects in several species demonstrate immunomodulatory potential. For example, in the human population, $\mathrm{HCHO}$ can cause increased sensitivity to multiple chemicals in individuals coexposed to formaldehyde (Ziem \& McTamney 1997, Sorg et al. 1998). Studies have shown formaldehyde to bind to human serum albumin, where it acts as a hapten (Li et al. 2007). A humoral immune response to the albumin-bound formaldehyde has been suggested as a useful biological marker for HCHO exposure. Dogs and rabbits have been shown to produce a measurable immune response to immunization with intravenous HCHO (Patterson et al. 1985). In experimental rodents, topical application of $\mathrm{HCHO}$ induced a dose-dependant activation of regional draining lymph nodes in rats (Arts et al. 1997) and also induced production of Th-1 inflammatory cytokine secretion in mice (Dearman et al. 1997). Lymph node weights have been increased significantly following oral exposure to $\mathrm{HCHO}$ in rats (Arts et al. 2008). Thus, mammals respond immunologically to $\mathrm{HCHO}$ exposure in a number of ways.
The present study evaluated several piscine immune parameters, including functional responses, following $\mathrm{HCHO}$ exposure. Doses used in the present work fall well within therapeutic ranges used commercially. Therapeutic regimens useful in the aquaculture industry range from short-term immersion in very high concentrations ( $\leq 15 \mathrm{~min}, 1000$ to $2000 \mathrm{ppm}$ ) through longterm exposure to low concentrations (up to $4 \mathrm{~h}, 15$ to 25 ppm) (Schnick 1974). Exposure to 200-300 ppm for $1 \mathrm{~h}$ has been considered typical in the industry (Buchmann et al. 2004). In addition, frequent long-term exposure to low concentrations of formalin (25 ppm, $4 \mathrm{~h}$, 4 times per week, over several months) is also used prophylactically (Bodensteiner et al. 1993).

In general, the present studies produced no-effect immunologic data for formadehyde. Spleen/body weight ratios, total cellularity, mitogen response, and mixed lymphocyte reactions were not significantly altered. Natural killer cell activity was not significantly changed. In this regard, the response of the piscine immune system was similar to that reported in a previous study examining similar endpoints in B6C3F1 mice in which no significant immunosuppression was observed (Dean et al. 1984).

Two significant changes were observed in the present work. First, peripheral blood lymphocytes were decreased by exposure to $150 \mathrm{ppm}$ formaldehyde. No change was observed in splenic lymphocyte number. There was limited evidence of increased lymphocytes in the pronephros, suggesting the possibility of sequestering of cells in this organ. This effect, if real, did not appear sufficient in magnitude to account for the decreased lymphocytes observed in peripheral circulation. Lymphocytes may also have been sequestered in some other compartment or tissue in response to $\mathrm{HCHO}$ exposure (e.g. thymus, mucosal, or non-lymphoid organ). The second change in $\mathrm{HCHO}$-exposed fish was a significant decrease in the number of progenitor cells in the pronephros. Changes affecting the progenitor compartments of immune cells are not likely to be immediately reflected in evaluation of parameters involving the lymphoid cellularity of peripheral organs or circulating blood, nor will such changes affect the function of mature lymphoid cells already in the periphery. Such cells may well be able to mount control-level immune response for some period of time. However, decreases in progenitor cells would ultimately be expected to affect the number of cells available to colonize the periphery and come to the defense of the organism. Should depletion in the progenitor compartment be protracted, effects in the periphery and, thus, in the immune competence of the individual could eventually manifest under conditions of stress, or in instances of immune challenge. Decreases in the progenitor ranks, therefore, may potentiate immunosuppression. 
It remains uncertain whether the cellular effects observed in the present study are immunotoxic effects. In rodents, a chemical-induced decrease in peripheral blood leukocyte counts has a relatively low predictive value for immunosuppression, such that actual immune suppression occurs only about half the time this effect is observed (Luster et al. 1993). Reduced numbers of hematopoietic progenitor cells appear to be a more sensitive indicator of immune suppression; however, data are lacking to calculate a predictive value (Holladay \& Smialowicz 2000). Thus, immune challenge assays are the next required step to determine if the present $\mathrm{HCHO}$ exposures may be immunosuppressive in fish. This will be important to determine, since the dose levels used in this work were similar to those routinely used in aquaculture facilities.

In conclusion, the present data suggest that certain components of the piscine immune system, specifically the lymphoid progenitor compartment, may be negatively affected by formaldehyde exposure. Damage to this compartment is particularly noteworthy, given possible delayed effects of chemical exposure on future immune response of the individual.

Acknowledgements. This work was supported by NIH Grant No. RO1-ES 07612-01 SRC and performed at the Aquatic Medicine Center of the Virginia-Maryland Regional College of Veterinary Medicine. We thank Dr. Stephen Smith, Director of the Aquatic Medicine Center at Virginia Tech, and Dr. Kristina Douglas, for their assistance with this project.

\section{LITERATURE CITED}

Ahmed SA, Gogal RM Jr, Walsh JE (1994) A new rapid and simple non-radioactive assay to monitor and determine the proliferation of lymphocytes: an alternative to $\left[{ }^{3} \mathrm{H}\right]$ thymidine incorporation assay. J Immunol Methods 170:211-224

Arts JH, Droge SC, Spanhaak S, Bloksma N, Pennincks AH, Kuper CF (1997) Local lymph node activation and IgE responses in brown Norway and Wistar rats after dermal application of sensitizing and no-sensitizing chemicals. Toxicology 105:417-436

Arts JH, de Jong WH, van Triel JJ, Schijf MA, de Klerk A, van Loveren H, Kuper CF (2008) The respiratory local lymph node assay as a tool to study respiratory sensitizers. Toxicol Sci 106:423-434

Balamurugan V, Kumar RM, Suryanarayana VV (2004) Past and present vaccine development strategies for the control of foot-and-mouth disease. Acta Virol 48:201-214

- Bodensteiner LR, Sheehan RJ, Lewis WM, Wills PS (1993) Effects of repetitive formalin treatments on channel catfish juveniles. J Aquat Anim Health 5:59-63

Buchmann K, Bresciani J, Jappe C (2004) Effects of formalin treatment on epithelial structure and mucous cell densities in rainbow trout, Oncorhynchus mykiss (Walbaum), skin. J Fish Dis 27:99-104

> Casanova M, Heck HA (1997) Lack of evidence for the involvement of formaldehyde in the hepatocarcinogenicity of methyl tertiary-butyl ether in CD-1 mice. Chem Biol Interact 105:131-143
Dean JH (2004) A brief history of immunotoxicology and a review of the pharmaceutical guidelines. Int J Toxicol 23: 83-90

> Dean JH, Lauer LD, House RV, Murray MJ and others (1984) Studies of immune function and host resistance in B6C3F1 mice exposed to formaldehyde. Toxicol Appl Pharmacol 72:519-529

Dearman RJ, Smith S, Basketter KA, Kimber I (1997) Classification of chemical allergens according to cytokine secretion profiles of murine lymph node cells. J Appl Toxicol 17: 53-62

Faisal M, Huggett RJ (1993) Effects of polycyclic aromatic hydrocarbons on the activity of lymphocytes of spot Leiostomus xanthurus. Mar Environ Res 35:121-124

Gogal RM Jr, Smith BJ, Holladay SD (1999) Tilapia (Oreochromis niloticus) dosed with azathioprine display immune effects similar to those seen in mammals, including apoptosis. Vet Immunol Immunopathol 68:209-227

Hart LJ, Smith SA, Smith BJ, Robertson JL, Holladay SD (1997) Exposure of tilapian fish to the pesticide lindane results in hypocellularity of the primary hematopietic organ (pronephros) and the spleen without altering activity of phagocytic cells in these organs. Toxicology 118: 211-221

Hilton J, Dearman RJ, Basketter DA, Scholes EW, Kimber I (1996) Experimental assessment of the sensitizing properties of formaldehyde. Food Chem Toxicol 24:571-578

Holladay SD, Smialowicz RJ (2000) Development of the immune system: differential effects of immunotoxicants depend on time of exposure. Environ Health Perspect 108(Suppl 3):483-490

Hudson L, Hay FC (1989) Practical immunology, Vol 3. Blackwell Scientific Publications, London

Iwanowicz LR, Blazer VS, McCormick SD, Vanveld PA, Ottinger CA (2009) Aroclor 1248 exposure leads to immunomodulation, decreased disease resistance and endocrine disruption in the brown bullhead, Ameiurus nebulosus. Aquat Toxicol 93:70-82

> Lahnsteiner F, Weismann T (2007) Treatment of ichthyophthiriasis in rainbow trout and common carp with common and alternative therapeutics. J Aquat Anim Health 19: 186-194

> Li H, Wang J, König R, Ansari GA, Khan MF (2007) Formaldehyde-protein conjugate-specific antibodies in rats exposed to formaldehyde. J Toxicol Environ Health A 70: 1071-1075

Luster MI, Portier C, Pait DG, Roesnthal GJ and others (1993) Risk assessment in immunotoxicology. II. Relationships between immune and host resistance tests. Fundam Appl Toxicol 21:71-82

Mackerer CR, Angelosanto FA, Blackburn GR, Schreiner CA (1996) Identification of formaldehyde as the metabolite responsible for the mutagenicity of methyl tertiary-butyl ether in the activated mouse lymphoma assay. Proc Soc Exp Biol Med 212:338-341

> MacLean RA, Fatzinger MH, Woolard KD, Harms CA (2006) Clearance of a dermal Huffmanela sp. in a sandbar shark (Carcharhinus plumbeus) using levamisole. Dis Aquat Org 73:83-88

Maddalena R, Russell M, Sullivan DP, Apte MG (2009) Formaldehyde and other volatile organic chemical emissions in four FEMA temporary housing units. Environ Sci Technol 43:5626-5632

> McCarthy MC, O'Brien TE, Charrier JG, Hafner HR (2009) Characterization of the chronic risk and hazard of hazardous air pollutants in the United States using ambient monitoring data. Environ Health Perspect 117:790-796 
McNary JE, Jackson EM (2007) Inhalation exposure to formaldehyde and toluene in the same occupational and consumer setting. Inhal Toxicol 19:573-576

Mennear JH (1997) Carcinogenicity studies on MTBE: critical review and interpretation. Risk Anal 17:673-681

Müller C, Ruby S, Brousseau P, Cyr D, Fournier M, Gagné F (2009) Immunotoxicological effects of an activated-sludgetreated effluent on rainbow trout (Oncorhynchus mykiss). Comp Biochem Physiol C 150:390-394

Murai K, Okano M, Kuramitz H, Hata N, Kawakami T, Taguchi S (2008) Investigation of formaldehyde pollution of tap water and rain water using a novel visual colorimetry. Water Sci Technol 58:1055-1060

Odeigah PG (1997) Sperm head abnormalities and dominant lethal effects of formaldehyde. Mutat Res 389:141-148

Patterson R, Harris KE, Grammer LC (1985) Canine antibodies against formaldehyde-dog serum albumin conjugates: induction, measurement, and specificity. J Lab Clin Med 106:93-100

Schnick RA (1974) Formalin as a therapeutant in fish culture. Literature Review 74-09, US Fish and Wildlife Service, Washington, DC

Smith DA, Schurig GG, Smith SA, Holladay SD (1999) Tilapia

Editorial responsibility: Helmut Segner,

Bern, Switzerland
(Oreochromis niloticus) and rodents exhibit similar patterns of inhibited antibody production following exposure to chemical inhibitors of humoral immune function. Vet Hum Toxicol 41:368-373

Sorg BA, Willis J, See RE, Hopkins B, Westberg HH (1998) Repeated low-level formaldehyde exposure produces cross-sensitization to cocaine: possible relevance to chemical sensitivity in humans. Neuropsychopharmacology 18: 385-394

Vasudeva N, Anand C (1996) Cytogenetic evaluation of medical students exposed to formaldehyde vapor in the gross anatomy dissection laboratory. J Am Coll Health 44:177-179

> Woodruff TJ, Axelrad DA, Caldwell J, Morello-Frosch R, Rosenbaum A (1998) Public health implications of 1990 air toxics concentrations across the United States. Environ Health Perspect 106:245-251

Zelikoff JT, Browser D, Squibb KS, Frenkel K (1995) Immunotoxicity of low level cadmium exposure in fish: an alternative animal model for immunotoxicological studies. $\mathrm{J}$ Toxicol Environ Health 45:235-248

Ziem G, McTamney J (1997) Profile of patients with chemical injury and sensitivity. Environ Health Perspect 105 (Suppl 2):417-436

Submitted: May 28, 2010; Accepted: August 5, 2010

Proofs received from author(s): September 13, 2010 